$\Phi=$

\title{
Determination of fingernail chromium, cadmium, and lead in tannery workers
}

\author{
Yen-Hsiung Liao \\ Department of Health Sciences, School of Public Health, Kaohsiung Medical University \\ E-mail: bany0309@yahoo.com.tw
}

\begin{abstract}
Purpose: To determine whether chromium, cadmium, and lead levels in human Fingernails reflected the exposure to workplace contamination in tanneries.

Approach: 49 exposed tanning workers and 33 controls were monitored for fingernail levels of chromium, cadmium, and lead by graphite furnace and hydride atomic absorption spectroscopy.

Results: The mean levels of fingernail chromium, cadmium, and lead in the exposed workers were significantly higher than those in the controls. In regression models for the tannery workers, the significant risk factor that affected the fingernail chromium, Cadmium, and lead level were occupational exposure, respectively. Current smoker it showed a significant change in trend of increased fingernail cadmium levels.

Conclusion: These findings indicate that chromium, cadmium, and lead absorbed from. Leather tanning compounds result in raised levels of chromium, cadmium, and lead in fingernails and that improvement of the industrial health should be more practiced in the tanneries in Taiwan.
\end{abstract}

Keywords: Tannery; Fingernails; Chromium; Cadmium; Lead.

\section{Introduction}

Leather tanning is a traditional and polluted industry. Leather manufacturing consists of four steps: pre-tanning and tanning, wet finishing, dry finishing, and packing (Gupta 1990). Heavy metals, including $\mathrm{Cr}, \mathrm{Cd}$, and $\mathrm{Pb}$ are generally used in the tanning and dyeing procedures that are known not essential for plants or animals and can be toxic to both (Haroun et al. 2007). For the reason, tannery workers may thus be exposed to undue amounts of these metals.

Biological monitoring of Cr levels by analysis of hair, blood, and urine in tannery workers had been documented (Saner et al. 1984, Randall \& Gibson 1987, Randall \& Gibson 1989). The use of fingernails to monitor industrial exposure to $\mathrm{Cr}, \mathrm{Cd}$, and $\mathrm{Pb}$ is well invested in many sectors and environments (Sukumar \& Subramanian 1992, Sukumar \& Subramanian 1992, Mehra \& Juneja 2005, Sukumar \& Subramanian 2007). Nevertheless, the levels of fingernail $\mathrm{Cr}, \mathrm{Cd}$, and $\mathrm{Pb}$ in tannery workers are still not known. Human nails as well as hair are non-invasive and biological samples for monitoring body burden of elements (Hopps 1976, Sukumar \& Subramanian 2007)... The fingernail's Cr, Cd, and Pb levels of tannery workers were determined in an attempt to establish whether they may reflect workplace contamination in tanneries.

\section{Methods}

\subsection{Study subjects}

We studied subjects from three tanneries in southern Taiwan. The study population consisted of 49 tannery workers. They were classified into three exposure categories based on their operational department, chemical use, and references (Saner et al. 1984, Ory et al. 1997): 1) 16 pre-tanning and tanning; 2) 18 wet finishing and dry finishing, and 3) 15 supervisor, plant services, and guards. The controls consisted of 33 persons who were not employed in industrial sectors. Each participant included in the study population completed a questionnaire, including information about age, cigarette smoking, working years, job histories, and operational department. The study subjects and controls had no overt signs of clinical disease. The study was approved by the Institutional Review Board of Kaohsiung Medical University. All participants were informed and signed consent forms.

\subsection{Biological monitoring}

Fingernails were scraped with clean stainless-steel clippers. A total of 3 grams of fingernails was sealed in the plastic cover till it was washed. All the fingernail clippings were stored in polyethylene tubes before washing. The samples were washed with nonionic detergent (Triton X-100) following a standardized washing procedure (Gammelgaard et al. 1991). The fingernails were soaked in acetone three times to remove external contamination and then rinsing them one time with deionized water, dried in an oven and stored in a desiccator (Sukumar \& Subramanian 2007).

Microwave dissolution technique was used to digest fingernail samples by a Model-MDS-2000 CEM remote microwave system (CEM, Matthews, NC). A fingernail sample $(100 \mathrm{mg})$ and $10 \mathrm{ml}$ of the Bi-acid solution (three $\mathrm{ml} 65 \% \mathrm{HNO} 3+1 \mathrm{ml} 30 \% \mathrm{H} 2 \mathrm{O} 2$ ) 
were transferred into a $80-\mathrm{ml}$ pressure-resistant polytetrafluoroethylene bottle. The sample was digested by seven steps to remove the interfering matrix $(\mathrm{S} 1: 10 \mathrm{~W}, 5$ minutes; $\mathrm{S} 2: 0 \mathrm{~W}, 30$ minutes; S3: $25 \mathrm{~W}, 15$ minutes; S4: $40 \mathrm{~W}, 20$ minutes; S5: 50 W, 10 minutes; S6: $10 \mathrm{~W}, 5$ minutes; S7: $60 \mathrm{~W}, 15$ minutes). Digested solution was evaporated completely to remove excess acid and then diluted with deionized water to $10 \mathrm{ml}$ for metal analysis. The levels of the metals were assayed by using GBC AAS model 906 plus with graphite 3000 after microwave dissolution. The optimal experimental conditions are given in Table 1.

Table 1: Graphite Furnace Parameters of $\mathrm{Cr}, \mathrm{Cd}$, and $\mathrm{Pb}$

\begin{tabular}{llll}
\hline Parameter & $\mathrm{Cr}$ & $\mathrm{Cd}$ & $\mathrm{Pb}$ \\
\hline Wavelength (nm) & 357.9 & 228.8 & 283.3 \\
Lamp current (mA) & 6.0 & 3.0 & 5.0 \\
Slit Width (nm) & 0.2 & 0.5 & 0.5 \\
Argon flow (L/min) & 3.4 & 3.4 & 4.2 \\
Drying temperature (0C) & 120 & 120 & 120 \\
Ashing temperature (OC) & 1100 & 300 & 400 \\
Atomization temperature (0C) & 2300 & 1700 & 1900 \\
Clean temperature (0C) & 2600 & 2200 & 2400 \\
\hline
\end{tabular}

All reagents used were purchased from Merk (Germany) and were of Suprapur grade. To establish the validity of our results, we used the Trace Metals 7878 APG Setpoint TM QC Standard (Analytical Products Group, Belpre, OH, USA) as a reference. Table 2 shows the accuracy and precision of the $\mathrm{Cr}, \mathrm{Cd}$, and $\mathrm{Pb}$ analysis.

Table 2: Accuracy and Precision of the Trace Metals 7879 Standard Analysis $(\mathrm{Mg} / \mathrm{Dl})$

\begin{tabular}{llll} 
ysis (Mg/D1). & $\mathrm{Cr}$ & $\mathrm{Cd}$ & $\mathrm{Pb}$ \\
\hline & $68.8 \pm 6.2$ & $130.4 \pm 11.8$ & $80.0 \pm 5.5$ \\
\hline Certified value & $66.7 \pm 7.3$ & $135.4 \pm 10.9$ & $77.6 \pm 4.8$ \\
Measure value (N=3) & -1.60 & 3.83 & -3.00 \\
$\begin{array}{l}\text { Accuracy (\%) } \\
\text { Precision (\%) Within-run }\end{array}$ & & & \\
& 6.84 & 5.14 & 4.33 \\
$(\mathrm{~N}=10)$ & & & \\
Day- to- day (N=10) & 10.94 & 6.19 & 8.05 \\
\hline
\end{tabular}

\subsection{Statistical Methods}

All results were presented as the value of mean $\pm \mathrm{SD}$. When two groups were compared, the Student's t test (normalized transformation) or Chi-square test was employed. The one-way analysis of variance test (ANOVA) and post-hoc statistic were used to compare the significant differences of metal levels in fingernails among the three operational departments, and the controls. The Pearson's correlation between each of measured $\mathrm{Cr}, \mathrm{Cd}$, and $\mathrm{Pb}$ levels in the various groups was calculated. The data were subjected to multiple linear regression models to examine the net effects and dose-response relation between exposure situation and fingernail metal concentrations. The limit of significance was set up at $\mathrm{p}<0.05$. All analyses were performed with the SPSS program (SPSS Inc., Chicago, IL) for Windows.

\section{Results}

\subsection{Distribution of demographic characteristic, and exposure biomarkers among the study subjects}

The demographic, and levels of metals in human's fingernails are showed in table 3 .

There were a significantly lower proportion of current smokers in the group of supervisor, plant services, and guards than in the pretanning and tanning workers, in wet, finishing and dry finishing workers, and in the controls. The mean age ( $42.82 \pm 12.24$ years $)$, levels of fingernail $\mathrm{Cr}(2.42 \pm 2.22 \mu \mathrm{g} / \mathrm{g})$, Cd $(1.51 \pm 0.54 \mu \mathrm{g} / \mathrm{g})$, and $\mathrm{Pb}(12.22 \pm 3.93 \mu \mathrm{g} / \mathrm{g})$ were significantly higher in the occupationally total exposed workers than in the controls. Using the one-way analysis of variance test and post post-hoc statistics, significant differences were found between pre-tanning and tanning workers and the controls in fingernail $\mathrm{Cr}$ levels, between wet, finishing and dry finishing workers and the controls in Fingernail $\mathrm{Cr}, \mathrm{Cd}$, and $\mathrm{Pb}$ levels, and between a group of supervisor, plant services, and guards and the controls in fingernail $\mathrm{Cr}$ levels. Fingernail $\mathrm{Cr}$ levels in the pre-tanning and tanning workers were also significantly higher than those in the wet, finishing and dry finishing workers, and in the supervisor, plant services, and guards. Fingernail Cd levels in the wet, finishing and dry finishing workers were also significantly higher than those in the pre-tanning and tanning workers and in the supervisor, plant services, and guards. Mean of working years $(12.53 \pm 6.47)$ in the supervisor, plant services was significantly lower than those in the pre-tanning and tanning workers, and in the wet, finishing and dry finishing workers, respectively. There was no significant difference of levels of fingernail $\mathrm{Pb}$ among the exposed subgroups.

Table 3: The Demographic, And Levels of Metals in Human's Fingernails among the Exposed Workers ( $\mathrm{N}=49)$ and the Controls $(\mathrm{N}=33)$.

Group Pre-tanning and Wet finishing and supervisor, plant Total controls tanning dry finishing services, and guards

$\begin{array}{lrrrrrrr}\text { Number } & 16 & 18 & & 15 & 49 & 33 \\ \text { Male } & 6 & 8 & & 8 & & 22 & 17 \\ \text { Smoker } & 5 & 7 & 1 & & 14 & & 9\end{array}$

Smoker

Working

years $24.06 \pm 12.55{ }^{\mathrm{d}} 20.39 \pm 10.63{ }^{\mathrm{f}} 12.53 \pm 6.47 \quad 19.18 \pm 11.12$

Age $49.06 \pm 12.5543 .00 \pm 10.8735 .53 \pm 10.2942 .82 \pm 12.24 * 37.45 \pm 9.75$ Years

Fingernail $4.83 \pm 2.5^{\mathrm{a}, \mathrm{d}, \mathrm{e}} 1.34 \pm 0.4^{\mathrm{b}, \mathrm{f}} 1.16 \pm 0.2^{\mathrm{c}} 2.42 \pm 2.2 * 0.82 \pm 0.2$ $\mathrm{Cr} \mu \mathrm{g} / \mathrm{g} \quad(1.66,8.26) \quad(0.51,1.86)(0.78,1.52)(0.51,8.26)(0.36,1.24)$ Fingernail $1.32 \pm 0.391 .87 \pm 0.59$ b,e,f $1.28 \pm 0.41 .51 \pm 0.54 * 1.16 \pm 0.4$ $\begin{array}{llllll}\mathrm{Cd} \mu \mathrm{g} / \mathrm{g} & (0.53,1.83) & (0.66,3.24) & (0.66,1.83) & (0.53,3.24) & (0.54,1.90)\end{array}$ Fingernail $11.28 \pm 3.613 .12 \pm 3.63 \mathrm{~b} 12.15 \pm 4.612 .22 \pm 3.93 * 9.33 \pm 4.6$ $\mathrm{Pb} \mu \mathrm{g} / \mathrm{g} \quad(6,019.0) \quad(6.8,9.0) \quad(6.6,20.2) \quad(6.0,20.2) \quad(3.3,20.1)$ $* \mathrm{P}<0.05$ total exposed workers vs. controls; ${ }^{\mathrm{a}} \mathrm{P}<0.05$ pre-tanning and tanning vs. controls; ${ }^{\mathrm{b}} \mathrm{P}<0.05$ wet finishing and dry finishing vs. controls; ${ }^{\mathrm{c}} \mathrm{P}<0.05$ supervisor, plant service, and guards vs. controls; ${ }_{\mathrm{P}}^{\mathrm{d}}<0.05$ pretanning and tanning vs. supervisor, plant service, and guards; ${ }^{\mathrm{e}} \mathrm{P}<0.05$ pre-tanning and tanning vs. wet finishing and dry finishing; ${ }^{\mathrm{P}}<0.05$ wet

finishing and dry finishing vs. supervisor, plant service, and guards

\subsection{Relationship of fingernail $\mathrm{Cr}, \mathrm{Cd}$, and $\mathrm{Pb}$}

Fingernail Cd levels were positively correlated $(\mathrm{p}<0.05)$ with the fingernail $\mathrm{Pb}$ in the total subjects, in the total exposed group, and in the wet, finishing and dry finishing workers, respectively (table 4). There were no correlation between fingernail $\mathrm{Cr}$ and $\mathrm{Cd}$, and $\mathrm{Pb}$ in the total subjects, in the total exposed group, and in the exposed subgroups, respectively.

Table 4: The Pearson's Correlation Coefficient between Fingernail Cr, $\mathrm{Cd}$, and $\mathrm{Pb}$ Levels

\begin{tabular}{llll}
\hline \multirow{2}{*}{ Group (numbers) } & $\begin{array}{ll}\mathrm{Cr} \text { vs. } \\
\mathrm{Cd}\end{array}$ & $\begin{array}{l}\mathrm{Cr} \text { vs. } \\
\mathrm{Pb}\end{array}$ & $\begin{array}{l}\mathrm{Cd} \text { vs. } \\
\mathrm{Pb}\end{array}$ \\
\hline Total (82) & -0.04 & 0.13 & $0.42^{*}$ \\
Exposed workers (42) & -0.26 & -0.06 & $0.44^{*}$ \\
Pre-tanning and tanning (16) & -0.33 & 0.25 & 0.08 \\
Wet finishing and dry finishing (18) & -0.00 & -0.36 & $0.65^{*}$ \\
Supervisor, plant services, and guards & -0.27 & 0.18 & 0.40 \\
(15) & 0.18 & 0.24 & 0.22 \\
Controls (33) & & &
\end{tabular}

$* \mathrm{P}<0.05$

\subsection{Dose-response relation between biomarkers and risk factors}

In stepwise regression models (table 5); we first used the controls as an external comparison group to examine fingernail $\mathrm{Cr}, \mathrm{Cd}$, and $\mathrm{Pb}$ levels. The regression coefficient $(\beta)$ of exposure situation was $0.37(\mathrm{p}<0.05)$ in fingernail $\mathrm{Cr}$ levels, $0.37(\mathrm{p}<0.05)$ in fin- 
gernail Cd levels, and $0.32(\mathrm{p}<0.05)$ in fingernail $\mathrm{Pb}$ levels, and the Regression coefficient $(\beta)$ of the current smokers was 0.35 in fingernail Cd levels.

Table 5: Predictors of the Fingernail $\mathrm{Cr}, \mathrm{Cd}$, and $\mathrm{Pb}$ Levels by Multiple Regressions in the Total Population and Among Tannery Workers.

\begin{tabular}{|c|c|c|c|c|c|c|}
\hline \multirow[b]{2}{*}{ Variables } & \multicolumn{2}{|r|}{$\mathrm{Cr}$} & \multicolumn{2}{|r|}{$\mathrm{Cd}$} & \multicolumn{2}{|r|}{$\mathrm{Pb}$} \\
\hline & $\beta$ & $p$ value $r^{2}$ & $\beta$ & $p$ value $r^{2}$ & $\beta$ & $\mathrm{p}$ value $\mathrm{r}^{2}$ \\
\hline $\mathrm{E}$ vs $\mathrm{C}(\mathrm{C}=0)$ & 0.37 & $0.00 \quad 0.20 *$ & 0.37 & $0.00 \quad 0.17 *$ & 0.32 & \multirow[t]{2}{*}{$0.00 \quad 0.11^{*}$} \\
\hline \multicolumn{3}{|c|}{ Current smoker $($ no $=0)$} & \multicolumn{2}{|r|}{$\begin{array}{lll}0.35 & 0.01\end{array}$} & & \\
\hline \multicolumn{3}{|c|}{ P\&T vs. $\mathrm{C}(\mathrm{C}=0) 0.830 .000 .62 *$} & -- & -- & -- & -- \\
\hline \multicolumn{3}{|l|}{$\begin{array}{l}\text { Finishing vs. } \\
\mathrm{C}(\mathrm{C}=0)\end{array}$} & 0.53 & $0.00 \quad 0.42 *$ & 0.33 & $0.030 .12 *$ \\
\hline \multicolumn{3}{|c|}{ Current smoker $($ no $=0)$} & 0.45 & $0.010 .40^{*}$ & & \multirow[b]{2}{*}{--} \\
\hline \multicolumn{6}{|l|}{$\mathrm{C}(\mathrm{C}=0)$} & \\
\hline P\&T vs. Service & 0.77 & $0.000 .47 *$ & -- & -- & -- & -- \\
\hline \multicolumn{3}{|c|}{ Finishing vs. Service -- -- } & 0.45 & $0.040 .26^{*}$ & -- & -- \\
\hline P\&T vs. Finishin & $\operatorname{g~} 0.73$ & $30.000 .46^{*}$ & -0.45 & $0.00 \quad 0.32 *$ & -- & -- \\
\hline \multicolumn{7}{|c|}{$\begin{array}{l}\text { E: Occupational exposure. C: controls. P\&T: Pre-tanning and tanning. } \\
\text { Finishing: Wet finishing and dry finishing. Service: Supervisor, plant ser- } \\
\text { vices, and guards. *p value }<0.05 \text { : significant difference, all data had been } \\
\text { normalized. All models were adjusted for age, sex, and working years. }\end{array}$} \\
\hline
\end{tabular}

However age and sex did not significantly affect the fingernail $\mathrm{Cr}$, $\mathrm{Cd}$, and $\mathrm{Pb}$ in the two comparison groups. We finally used the controls as an internal comparison group. The pre-tanning and tanning workers had fingernail $\mathrm{Cr}$ levels that were higher By $82.6 \%$ ( $p<0.05)$ than those in the controls. The wet finishing and dry finishing workers had fingernail $\mathrm{Cr}, \mathrm{Cd}$, and $\mathrm{Pb}$ levels that were higher by $63.4 \%, 53.0 \%$, and $33.0 \%$ (all $\mathrm{p}<0.05$ ) than those in the controls. Furthermore, the regression of coefficient $(\beta)$ of current smoker was $0.45(\mathrm{p}<0.05)$ in fingernail $\mathrm{Cd}$ levels. The Supervisor, plant services, and guards had fingernail $\mathrm{Cr}$ levels that were higher by $62.1 . \%(\mathrm{p}<0.05)$ than those in the controls. Occupational exposure was the most common risk factor correlated with fingernail $\mathrm{Cr}, \mathrm{Cd}$, and $\mathrm{Pb}$, respectively. The smoking status was another risk factor that correlated with fingernail $\mathrm{Cd}$ levels significantly $(\mathrm{p}<0.05)$.

\section{Discussion}

The study showed an elevated fingernail $\mathrm{Cr}, \mathrm{Cd}$, and $\mathrm{Pb}$ levels in tannery workers.

When compared with the controls. A post-hoc analysis showed that pre-tanning and tanning workers, wet finishing and dry finishing workers, and supervisor, plant services, and guards had significantly higher mean fingernail $\mathrm{Cr}$ levels than the controls. The wet finishing and dry finishing workers had higher mean fingernail $\mathrm{Cd}$ levels than the controls. These results suggest that heavy exposure to $\mathrm{Cr}, \mathrm{Cd}$, and $\mathrm{Pb}$ metals may affect human fingernail $\mathrm{Cr}, \mathrm{Cd}$, and $\mathrm{Pb}$ levels in leather manufacturing.

The process of tanning consists of the transformation of anima skin to leather. The obtained hide is heavily treated with $\mathrm{Cr}$ compound in the tanning department, then dyeing with $\mathrm{Cr}, \mathrm{Cd}$ and $\mathrm{Pb}$ salts to obtain leather in the wet and dry finishing department. These metals were also found as contamination in tannery sludge (Haroun. et al. 2007, Tariq et al. 2006). The pre-tanning and tanning workers had significantly higher fingernail $\mathrm{Cr}$ levels than the wet finishing and dry finishing workers, and group of supervisor, plant services, and guards. The wet finishing and dry finishing workers had significantly higher fingernail $\mathrm{Cd}$ than the pretanning and tanning workers, and group of supervisor, plant services, and guards. These results reflect that use of leather Tanning and dying compounds could reflect in raised levels of $\mathrm{Cr}, \mathrm{Cd}$, and $\mathrm{Pb}$ in fingernails and that fingernails may be used as a monitor of occupational exposure to metals in tannery.

In multiple regression models, occupational exposure was the most risk factor correlated with increased fingernail $\mathrm{Cr}, \mathrm{Cd}$, and $\mathrm{Pb}$ levels. Current smoker as another risk factor was also correlated with increased fingernail Cd levels in the study subjects.
Some studies suggested that cadmium levels observed high in fingernails were related to tobacco smoking (Sukumar \& Subramanian 1992, Sukumar \& Subramanian 2007).

Their common suggestion is in agreement with our results. Age, and sex were not found influencing levels of metals in the fingernails. Similar observation has been made. For the studies of Sukumar \& Subramanian, and Hayashi et al (Sukumar \& Subramanian 1992. Hayashi et al. 1993). Length of employment might reflect the accumulated levels of biological exposure markers. However, fingernail $\mathrm{Cr}, \mathrm{Cd}$, and $\mathrm{Pb}$ levels were not correlated with working years in our studies. It implied that fingernail levels may be similar to serum or urine as a biomarker of current metals exposure, and the mechanism of length of employment on fingernail metal should be further investigated.

There were very limited exposure studies that conducted with the levels of $\mathrm{Cr}, \mathrm{Cd}$, and $\mathrm{Pb}$ in the fingernails of normal humans. Fingernail $\mathrm{Cr}$ levels in the controls was between $0.36 \mu \mathrm{g} / \mathrm{g}$ and 1.24 $\mu \mathrm{g} / \mathrm{g}$, with a mean value of $0.82 \pm 0.24 \mu \mathrm{g} / \mathrm{g}$. This result is in good agreement with the values $(0.9 \mu \mathrm{g} / \mathrm{g})$ reported by Kasperek et al (Kasperek et al. 1984), and Sukumar and Subramanian (0.9 0.1 $\mu \mathrm{g} / \mathrm{g}$ ) (Sukumar \& Subramanian 1992). Fingernail Cd levels in the controls was between $0.54 \mu \mathrm{g} / \mathrm{g}$ and $1.90 \mu \mathrm{g} / \mathrm{g}$, with a mean value of $1.16 \pm 0.38 \mu \mathrm{g} / \mathrm{g}$. This result is in good agreement with the values $(1.1 \pm 0.2)$ reported by Sukumar and Subramanian (Sukumar \& Subramanian 1992), and Nowak and Chmielnicka $(1.2 \pm 1.3 \mu \mathrm{g} / \mathrm{g})($ Nowak \& Chmielnicka 2000).

Fingernail $\mathrm{Pb}$ levels in the controls was between $3.33 \mu \mathrm{g} / \mathrm{g}$ and $20.09 \mu \mathrm{g} / \mathrm{g}$, with a mean value of $9.33 \pm 4.59 \mu \mathrm{g} / \mathrm{g}$. This result is in good agreement with the values $(9.0 \pm 1.0 \mu \mathrm{g} / \mathrm{g})$ reported by Sukumar and Subramanian (Sukumar \& Subramanian 1992), and Wilhelm et al $(8.5 \mu \mathrm{g} / \mathrm{g})$ (Wilhelm et al. 1991).The mean level of fingernail $\mathrm{Cr}(1.16 \pm 0.02 \mu \mathrm{g} / \mathrm{g})$ was significantly higher in the group of supervisor, plant services, and guards than in the controls, as well as their fingernail Cr levels were higher by $62.1 \%$ (p < 0.05 ) than those in the controls. Ory et al suggested that nontanning workers, such as packers, and plants services often had chemicals of exposures as they move from one section to the other during their daily work (Ory et al. 1997). Based on the above results, we suggest that improvement of the workplace through adequate ventilation should be more practiced in the tannery.

The limitation of this study is its cross-sectional design. Because the biological limit value of fingernail $\mathrm{Cr}, \mathrm{Cd}$, and $\mathrm{Pb}$ are not well known, more work will be warranted to clarify the relationship of metals exposure and health effects.

\section{Acknowledgments}

This project was supported by a grant from National Science Committee Taiwan (89-2320-B-037-027).

\section{References}

[1] Gammelgaard B, Peters K, \& Menno T (1991). Reference values for the nickel concentration in human fingernails. J Trace Elem Electrol Health Dis 5, 121 - 123 .

[2] Haroun M, Idris A, \& Syed Omar SR (2007). A study of heavy metals and their fate in the composting of tannery sludge. Waste Management 27, 1541-1550. http://dx.doi.org/10.1016/j.wasman.2006.09.006.

[3] Hayashi M, Yamamoto K, Yoshimura M, Hayashi H, \& Shitara A (1993). Cadmium, lead, and zinc concentrations in human fingernails. Bull Environ Contam Toxicol 50, $547 \quad$ - 553. http://dx.doi.org/10.1007/BF00191244.

[4] Hopps HC (1976). The biologic bases for using hair and nail for analyses of trace elements. Sci Total Environ 7, 71 - 89. http://dx.doi.org/10.1016/0048-9697(77)90018-3.

[5] Kasperek K, Iyengar GV, \& Feinendegen LE (1982). Multielement analysis of fingernail, scalp hair and water samples from Egypt (a preliminary study). The Science of the Total Environment 22, 149 - 168. http://dx.doi.org/10.1016/0048-9697(82)90032-8. 
[6] Mehra R, \& Juneja M (2005). Fingernails as biological indices of metal exposure. J Biosci 30, $253 \quad-257$. http://dx.doi.org/10.1007/BF02703706.

[7] Nowak B, \& Chmielnicka J (2000). Relationship of lead and cadmium to essential elements in hair, teeth, and nails of environmentally exposed people. Ecotoxicology and Environmental Safety 46, 265 - 274. http://dx.doi.org/10.1006/eesa.2000.1921.

[8] Ory FG, Rahman FU, Katagade V, Shukla A, \& Burdorf A (1997). Assessment of exposure to chemical agents and ergonomic stressors in tanneries in Kanpur, India. American Industrial Hygiene Association Journal 58, 732 - 739. http://dx.doi.org/10.1080/15428119791012388.

[9] Randall JA, \& Gibson RS (1987). Serum and urine chromium as indices of chromium status in tannery workers. Proc Soc Exp Biol Med 185, 16 - 23. http://dx.doi.org/10.3181/00379727-185-42510.

[10]Randall JA, \& Gibson, RS (1989). Hair chromium as an index of chromium exposure of tannery workers. British Journal of Industrial Medicine 46, 171- 175. http://dx.doi.org/10.1136/oem.46.3.171.

[11] Saner G, Yuzbasiyan V, \& Gigdem S (1984). Hair chromium concentration and chromium excretion in tannery workers. British Journal of $\begin{array}{lllll}\text { Industrial } & \text { Medicine } & 41, & 263 & -\end{array}$ http://dx.doi.org/10.1136/oem.41.2.263.

[12] Sukumar A \& Subramanian R (1992). Elements in hair nails of urban residents of New Delhi. CHD, hypertensive, and diabetic cases. Biol Trace Elem Res 34, 89 - 97. http://dx.doi.org/10.1007/BF02783901.

[13]Sukumar A \& Subramanian R (1992). Elements in hair nails of residents from a village adjacent to New Delhi. Influence of place of occupational and smoking habits. Biol Trace Elem Res 34, 99-105. http://dx.doi.org/10.1007/BF02783902.

[14] Sukumar A \& Subramanian R (2007). Relative element levels in the paired samples of scalp hair and fingernails of patients from New Delhi. Science of the Total Environment 372, 474 - 479. http://dx.doi.org/10.1016/j.scitotenv.2006.10.020.

[15] Tariq SR, Shah MH, Shaheen N, Khalique A, Manzoor S, \& Jaffar M (2006). Multivariate analysis of trace metal levels in tannery effluents in relation to soil and water: A case study from Peshawar, Pakistan. Journal of Environmental Management 79, 20 - 29. http://dx.doi.org/10.1016/j.jenvman.2005.05.009.

[16]Wilhelm M, Hafner D, Lombeck I, \& Ohnesorge FK (1991). Monitoring of cadmium, copper, lead and zinc status in young children using toenails: comparison with scalp hair. The Science of the Total Environment 103, 199 - 207. http://dx.doi.org/10.1016/00489697(91)90145-5. 